\title{
‘THE MANAGEMENT INDICATOR' FROM THE POINT OF VIEW OF AN URBAN ASSESSMENT
}

\author{
J.E.R. NIETO ${ }^{1}$, L.S. DA SILVA ${ }^{1}$, V. MURTINHO ${ }^{2}$ \& C. RIGUEIRO 3 \\ ${ }^{1}$ ISISE, Department of Civil Engineering, University of Coimbra, Portugal. \\ ${ }^{2} \mathrm{CES}$, Department of Architecture, University of Coimbra, Portugal. \\ ${ }^{3}$ ISISE, School of Technology, Polytechnic Institute of Castelo Branco, Portugal.
}

\begin{abstract}
The 'Management indicator' is one of the less prioritized indicators when we analyze the existing urban sustainable assessment methods. Nevertheless, and according to the opinion of some experts, this indicator should be one of the main as it deals with the involvement of local entities (communities, agencies and government) working together to improve the public services and quality of life of the inhabitants of a specific area. It recognizes the uniqueness of each place, ensuring that the community facilities are properly maintained and are appropriate to the existing population density (PD) of the area, so that a sense of ownership and responsibility is promoted. The main contribution of this paper is to give a complete panorama of the analysis and evaluation for the management indicator, as well as emphasize the importance of this indicator when we are making a sustainable assessment for urban areas or when we are trying to rehabilitate existing neighborhoods.

Keywords: management indicator, rehabilitation of urban areas, sustainable assessment tools.
\end{abstract}

\section{INTRODUCTION}

The interest towards sustainability performance has increased rapidly over the last decades, being developed in the construction sector, different methodologies to assess sustainability at different scales (building level and urban level). Both types of assessment methodologies are of primary importance in order to promote the sustainable development and to generate strategies for improving our environment. Nonetheless, over the past years the paradigm of sustainability assessment tools has been focused on the built environment scale or urban level, as it is in the cities as a whole, where it can be analyzed a more or less sustainable behavior [1].

Cities of today are concerned with its evolution and development, because currently it is increasingly frequent to see the lack of planning and the high concentration of people on them. This causes environmental, social and cultural deterioration and problems, such as: socio-spatial segregation, overcrowding, marginalization, environmental pollution, vehicular congestion, waste production, between others [2]. It is for this reason that the current cities have a motivation for developing and apply different tools for assessing Sustainable Development at urban areas.

Among the main assessment tools for developing an urban level evaluation, we can find: BREEAM Communities, BREEAM ES Urbanismo, LEED for Neighborhood Development, SBTool $^{\mathrm{PT}}$ for Urban Planning, CASBEE for Cities, CASBEE for Urban Development, DGNB New Urban Districts, Green Star Communities, BCA Green Mark for Districts, 
SILENT, SPeAR, Building for Life (BfL), the Egan Review and the UISA methodology. Each of these systems has different indicators and different perspectives of the sustainable requirements, but all of them have the common objective of helping in the evaluation of sustainability and proposing correct actions to make sustainable societies [3].

However, and besides the important efforts that these methodologies have done, they are still presenting some limitations among which are the lack of analysis in management, operation and maintenance within the analyzed area. For this reason, in this paper, we are presenting the study and analysis of the 'Management' indicator seen from the point of view of a new urban methodology, the UISA (Urban Integral Sustainable Assessment) tool, which is being developed as part of a PhD thesis at the University of Coimbra in Portugal.

\section{SUSTAINABLE INDICATORS - AN INTRODUCTION TO THE MANAGEMENT INDICATOR}

The use of sustainability indicators is essential for an integrated system approach, because these measurable aspects are useful for monitoring changes on a system, facilitating the decision making by translating collected data into manageable units of information [4] and they help to address challenges of sustainability as they cover multiple issues and consider linkage among them. Nowadays, among the main sustainable assessment methods for evaluating the urban level, it can be found 338 different indicators, which are grouped into the four dimensions of Sustainability: Environment, Social, Economic and Management.

As it can be noticed, it exists a huge number of indicators; and despite that, there is just one which concerns to the control and administration of the facilities of the analyzed area. This indicator is known as 'the Management indicator'.

\subsection{The management indicator in existing urban sustainable tools}

The management indicator represents one of the main indicators of the four pillar of sustainability denominated "Political, Institutional or Management" [5]. This indicator gives the part related with the control, operation, monitoring and maintenance of a place and because of its importance it can be analyzed in the four city scales (city, district, neighborhood and block) [6] and it covers the analysis of four main topics: Long-term and effective project management (LE); Quality assurance (QA); Sustainability management (SM) and PD.

Presently there are only few urban sustainable methodologies that takes into consideration the study and evaluation of this indicator. These methodologies are:

- BREEAM Communities.

- BREEAM ES Urbanismo.

- BCA Green Mark for Districts.

- SBTool $^{\mathrm{PT}}$ for Urban Planning.

- DGNB New Urban Districts.

Nevertheless, the criteria that each of these methodologies has for evaluating this indicator, is few and poor, generating usually a subjective evaluation and poorly justified. For this reason, the UISA methodology has been focused on the study of the Management indicator as one of its essential indicators, obtaining the information necessary to generate an objective 
assessment of this indicator by analyzing the parameters of the existing methodologies and with the study of relevant information to the topic.

\subsection{The UISA methodology}

The Urban Integral Sustainable Assessment method is being developed as a part of a $\mathrm{PhD}$ thesis at the University of Coimbra, Portugal. It tries to be a comprehensive tool for sustainable urban assessment at a neighborhood level, it arises from the necessity of solving the negative, weak and controversial aspects of the existing methodologies and with the idea of being a more objective sustainable assessment.

Its main objective is to be an integral, balanced and justified evaluation about the important aspects for generating sustainable places, so it contemplates the good aspects of the existing methodologies and tries to improve all the limitations and deficiencies that they present.

According to its structure, the UISA methodology is formed by 2 main categories (Urban morphology and Urban syntax), which are divided into 8 subcategories (From Urban Morphology: Architectural design quality of buildings; Physiognomy and urban image quality; Connectivity and mobility; Planned density. And from Urban Syntax: Sustainable buildings; Mixed-use community; Infrastructure and services; Future strategies) and uses 38 indicators obtained from the compendium of existing indicators to assess sustainability at an urban level.

From the 38 indicators that forms the UISA methodology, only 9 of them were selected as mandatory indicators, this means that these indicators are the minimum necessary to perform a comprehensive assessment of sustainability at the urban level. The selection of the mandatory indicators was done according to the opinion of different experts around the world, through an assessment survey and with the use of a percentage inquiry and the Analytical Hierarchy Process (AHP) system (multi-criteria system) it was obtained the weight of each indicator. The 9 mandatory indicators of UISA methodology are: Management, Economic viability, Flexibility and innovation, Waste management, Energy, Road infrastructure and equipment, Water, Future provisions and connections, and Population needs and priorities.

\section{THE MANAGEMENT INDICATOR FROM THE POINT OF VIEW OF THE UISA METHODOLOGY}

As it was mentioned before, the management indicator forms part of one of the nine mandatory indicators of the UISA methodology. It is one of the 3 indicators that form the planned density subcategory which at the same time is part of the urban morphology category.

For the proper study of the management indicator, the UISA methodology separates the criteria of the management indicator that is applied for the analysis of existing neighborhoods, as the criteria and study parameters varies according to their level of applicability.

\subsection{The management indicator}

This indicator represents an approach that involves local entities (communities, agencies and government) working together to improve the public services and quality of life of the inhabitants of a specific neighborhood. 
As it was mentioned before, it covers the analysis of four main topics: LE; QA; SM and PD; with the aim of recognize the uniqueness of each place, ensuring that the community facilities are properly maintained and are appropriate to the existing PD of the area, so that a sense of ownership and responsibility is promoted.

\subsubsection{Objective}

The analysis of the management indicator is based on five main objectives:

1. To encourage the integration of different agents into the planning, design and management of the analyzed area.

2. To adopt an environmental friendly management system which supports communities in active involvement in managing and maintaining of public facilities.

3. To promote a constant improvement of the urban environment through monitoring of strategies and plans of urban conservation.

4. To endorse an integrated, comprehensive, strategic and proactive urban development management.

5. To promote a balanced PD, this means that there is a sufficient number of people and urban services to meet the basic parameters of endowments, housing, open spaces and mobility means.

\subsubsection{Description of the criteria to be evaluated}

3.1.2.1 Long-term and effective project management This criterion involves the identification of advisory organizations that aid in the stages of management and maintenance of facilities and urban infrastructure of the study area. It is also responsible for studying the existence of a plan for monitoring and management of the urban facilities and the proper implementation of it by the corresponding stakeholders.

3.1.2.2 Quality assurance This criterion has to do with the requirements of the operational management system, the quality of the goals proposed in the strategies of community management of facilities; the parameters that have to be involved in the management manuals and standards, as well as the upgrade of these guidelines into action programs.

3.1.2.3 Sustainability management This criterion comprises the adoption of an environmental friendly management system by obtaining a certification relating to an effective management by the corresponding entities; the implementation of an intelligent monitoring and maintenance system of the environmental aspects which involves amortization costs of existing infrastructures; and the proper dissemination of results (on time and media resources) to sensitize users.

3.1.2.4 Population density This criterion involves the relationship between the number of people and the surface on which are. It has a direct relationship with the kind of neighborhood model that is being analyzed (compact neighborhood [ideal PD $=450$ hab./ha] vs dispersed neighborhood [ideal PD $=285$ hab./ha]), so it is necessary to note that the concept of high and low density is variable according to the context. A high density of population affects us more about our quality of life, although there is less environmental impact in terms of consumption; and a low density, pollutes less, but consume more resources, so the objective of this criteria is to analyze a balanced PD according to each case study. 


\subsubsection{Items required for evaluation}

The necessary documentation to prove the existence of the selected points of the calculation process, such as:

1. Copy of the strategy of community management of facilities, it can be a simple guide, an operational manual or a regulation.

2. Evidence of the existence of a management structure inside of the area.

3. Documentation where the support sources are identified, such as the Community Development Trust (CDT), the public sector, private business and other community groups, and the confirmation in regards of their acceptance of associated roles and responsibilities of each stakeholder.

4. Evidence proving how the strategy of community management has created pilot projects.

5. Information related to the pilot projects.

6. Copy of the certifications of effective management obtained by the local entities.

7. Proof of existence of a monitoring and maintenance system of the environmental aspects.

8. Evidence showing the existence of a PD analysis.

\subsubsection{Calculation process}

The Management indicator is evaluated through the calculation of the Management indicator index $\left(\mathrm{I}_{\mathrm{M}}\right)$, which represents the relation between the four analyzed criteria (LE; QA; SM and PD) that are weighted using the AHP system.

The $\mathrm{I}_{\mathrm{M}}$ is obtained by applying the following equation:

$$
\mathrm{I}_{\mathrm{M}}=(0.285 \mathrm{LE}+0.285 \mathrm{QA}+0.145 \mathrm{SM}+0.285 \mathrm{PD}) \times 100 \%(1)
$$

To obtain the value for each of the four criteria, it is necessary to fill out the information presented on Table 1, which are the quantification of the relevant parameters with its corresponding weights.

After the quantification of all the parameters, it is carried out the normalization of these values. Each parameter value should be normalized in order to set a dimensionless value that expresses the neighborhood performance evaluation in relation to the benchmarks (optimum values and conventional practice values). In the normalization process, it is used the equation of Diaz- Balteiro, which is:

$$
\begin{aligned}
\text { Normalized value }=1- & (\text { optimum value- actual value })(2) \\
& (\text { optimum value- conventional value })
\end{aligned}
$$

The use of eqn (2) converts the value of the four parameters into a dimensionless scale, where the value 0 corresponds to the level of conventional practice and value 1 to the best practice or optimum value.

The values obtained with the normalization of each parameter, have to be evaluated in eqn (1) $<$ Management indicator index $\left(\mathrm{I}_{\mathrm{M}}\right)>$, in order to obtain a total value which represents the level of sustainability for the Management indicator. This value determines the status of the neighborhood and the quality of sustainable development in terms of administration, control, monitoring and maintenance of facilities and the performance thereof. To make easier the understanding of the results, the numerical values are converted into a qualitative scale (Table 2). 
Is worth mentioning that no indicator alone is a measure of sustainability, as it has to be considered in conjunction with other indicators presented, so the compendium of all variables can show a full view of sustainable development of a district.

Table 1: Evaluation criteria for management indicator.

\begin{tabular}{cc}
\hline Evaluation criteria & Weighting \\
\hline Long-term and effective project management [LE] & \\
\hline
\end{tabular}

In the Neighborhood exists a management structure well defined.

$12.50 \%$

. It has been established a Community Development Trust (CDT) in charge $25.00 \%$
of support in the management of the neighborhood. CDT's are communi-
t.
t.
t.
ownershed organizations that use self-help trading for social purpose, and
environmental benefits in the area. They are independent, but work with
other groups [7].

Existence of a strategy of community management of facilities.

$12.50 \%$

ह The strategy is an operational manual, or a regulation for the operation and maintenance of the community facilities.

The existing plan for monitoring and management of the urban facilities $25.00 \%$ is properly implemented by the corresponding stakeholders.

Quality assurance [QA]

The operational management system adopted presents a multi-sectoral

$10.00 \%$

and cross-sectional approach. This with the aim of allow an adequate

interdependence of economic, ecological, demographic, social, and po-

litical factors of urban development.

The neighborhood management strategy provides a spatial interdepen-

dency. This means that its goals follow the specific interests of the neigh-

borhood, but these interests are linked to the ones of the city; it must be

seen a relationship between the city as a whole and the urban-regional

area.

The strategy permits flexible responses to unpredictable changes.

$10.00 \%$

The goals and quality standards of the management strategies are updated $10.00 \%$

I. according to the basis of monitoring and evaluation.

The goals presented in the management scheme are determined to gener- $10.00 \%$ ate a benefit and improvement of the place.

A detailed analysis for setting the local actions of the neighborhood has

done and are exposed in the strategy.

The guidelines address minimum five of the next key strategic areas: Architectural and neighborhood character; Housing and habitability; Mobil- 


\begin{tabular}{|c|c|c|}
\hline & Evaluation criteria & Weighting \\
\hline$\frac{\tilde{\Xi}}{2}$ & $\begin{array}{l}\text { Instead of supplying a detailed catalogue of goals and measures, the } \\
\text { guidelines formulate principles that are implemented in pilot projects. }\end{array}$ & $20.00 \%$ \\
\hline$\frac{\tilde{0}}{0}$ & $\begin{array}{l}\text { The pilot projects are drawn up with the intensive participation of the } \\
\text { various stakeholders (various professional chambers, associations, com- } \\
\text { panies, government and the public). }\end{array}$ & $10.00 \%$ \\
\hline
\end{tabular}

Sustainability management [SM]

\begin{tabular}{|c|c|c|}
\hline.$\simeq$ & $\begin{array}{l}\text { Any of the local entities are certified with ISO } 14000 \text { (is a family of stan- } \\
\text { dards related to environmental management). }\end{array}$ & $8.00 \%$ \\
\hline$\stackrel{\overrightarrow{0}}{0}$ & $\begin{array}{l}\text { Any of the local entities are certified with ISO } 9000 \text { (a quality management } \\
\text { standard, designed to help institutions to ensure that they meet the needs of } \\
\text { customers while meeting the requirements related to a product [8]). }\end{array}$ & $8.00 \%$ \\
\hline & Electricity consumption. & $4.00 \%$ \\
\hline & Drinking water consumption. & $4.00 \%$ \\
\hline & Gas distribution. & $4.00 \%$ \\
\hline 0 & Waste production. & $4.00 \%$ \\
\hline ह & Paving (like the PSI or the SCRIM system). & $4.00 \%$ \\
\hline$\sqrt{n}$ & Sewerage (like SITE - rain sensing system). & $4.00 \%$ \\
\hline$\stackrel{b 0}{=}$ & Public transportation. & $4.00 \%$ \\
\hline$=$ & Traffic signs. & $4.00 \%$ \\
\hline ฮี & Traffic lights. & $4.00 \%$ \\
\hline & Street lighting. & $4.00 \%$ \\
\hline & Urban woodland. & $4.00 \%$ \\
\hline & Irrigation of public spaces. & $4.00 \%$ \\
\hline & Cleanup of public space. & $4.00 \%$ \\
\hline & Monthly. & $20.00 \%$ \\
\hline ฮ & Bimonthly. & $16.00 \%$ \\
\hline$\beth$ & Quarterly. & $12.00 \%$ \\
\hline$\overline{0}$ & Semiannual. & $8.00 \%$ \\
\hline & Annual. & $4.00 \%$ \\
\hline 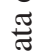 & Internet. & $4.00 \%$ \\
\hline & Press (printing or digital). & $4.00 \%$ \\
\hline & For consultation in a public building. & $4.00 \%$ \\
\hline \multicolumn{3}{|c|}{ Population density [PD] } \\
\hline & Number of inhabitants of the analyzed neighborhood: & Hab. \\
\hline & Dimension of the urban area analyzed. & $\mathrm{Km}^{2}$ \\
\hline & Population density (total population / total land area) & Hab. / $\mathrm{Km}^{2}$ \\
\hline & Kind of neighborhood model (compact or dispersed) & --- \\
\hline
\end{tabular}


Table 2: Evaluation qualitative scale.

\begin{tabular}{ll}
\hline Values of $\mathrm{I}_{\mathrm{M}}$ & Qualitative scale \\
\hline bigger than $100 \%$ & $\mathrm{~A}+$ \\
between $81 \%$ and $100 \%$ & $\mathrm{~A}$ (Best practice) \\
between $61 \%$ and $80 \%$ & $\mathrm{~B}$ (Very good practice) \\
between $41 \%$ and $60 \%$ & $\mathrm{C}$ (Good practice) \\
between $21 \%$ and $40 \%$ & $\mathrm{D}$ (satisfactory practice) \\
between $0 \%$ and $20 \%$ & $\mathrm{E}$ (conventional practice) \\
lower than $0 \%$ & $\mathrm{~F}$ (unsustainable practice) \\
\hline
\end{tabular}

\section{STUDY CASE - BAIXA OF COIMBRA, PORTUGAL}

In order to illustrate the applicability of the management indicator, the city of Coimbra, Portugal was chosen as a focal point. Coimbra is a medium-size city in Portugal, with a population of more than 100,000 inhabitants [9] and a territorial extension over 3,000 ha. It is located in the coastal region of Portugal, halfway between Lisbon and Oporto [10] (Fig. 1).

Because of its topography, downtown Coimbra is divided into two main areas: Alta which is the upper part and is largely occupied by the main complex of the University and Baixa which is the lower part and is a medieval core, historically associated with the original core of the city; it is the city center of Coimbra [10] and is composed by the parish known as Union of Parishes of Coimbra which was formed in 2013 under a national administrative reform that allows the aggregation of the old parishes of São Bartolomeu, Santa Cruz, Almedina and Sé Nova.

For the applicability scale of the management indicator, a neighborhood of Baixa was chosen as the study area, it has an area of $0.04638 \mathrm{~km}^{2}$ and it is illustrated in Fig. 2.

This study area is mainly residential (it has 355 inhabitants), so the use of an efficient management system of facilities is of primary importance. However, in this neighborhood it cannot be appreciated a well-structured and defined management system. This is possible to see when the management indicator analysis is performed.

\subsection{The Management indicator evaluation}

To carry out the analysis of management indicator, all the evaluation parameters presented in section 3.1.4 were analyzed. Among the most important considerations of the analysis, it was observed that even though on the analyzed area exists a management structure well defined, it doesn't have a CDT. Also the neighborhood has different strategies for building, rehabilitation and conservation of the area, which are established in regulations (Plano de Urbanização, Plano Director Municipal, Regulamento de Edificação e Recuperação, Regulamento Municipal de Urbanização e Edificação, Regulamento Urbano de Reabilitação urbana). Likewise, it can be seen that these strategies formulate principles that are implemented in pilot projects.

However, the Baixa neighborhood does not have an intelligent monitoring and maintenance system for any of its facilities and services, and according to the expectations of population density, it presents a very low population index (77 hab./ha.). Therefore, the $I_{M}$ has a value of $39 \%$, which translating into a qualitative scale is 


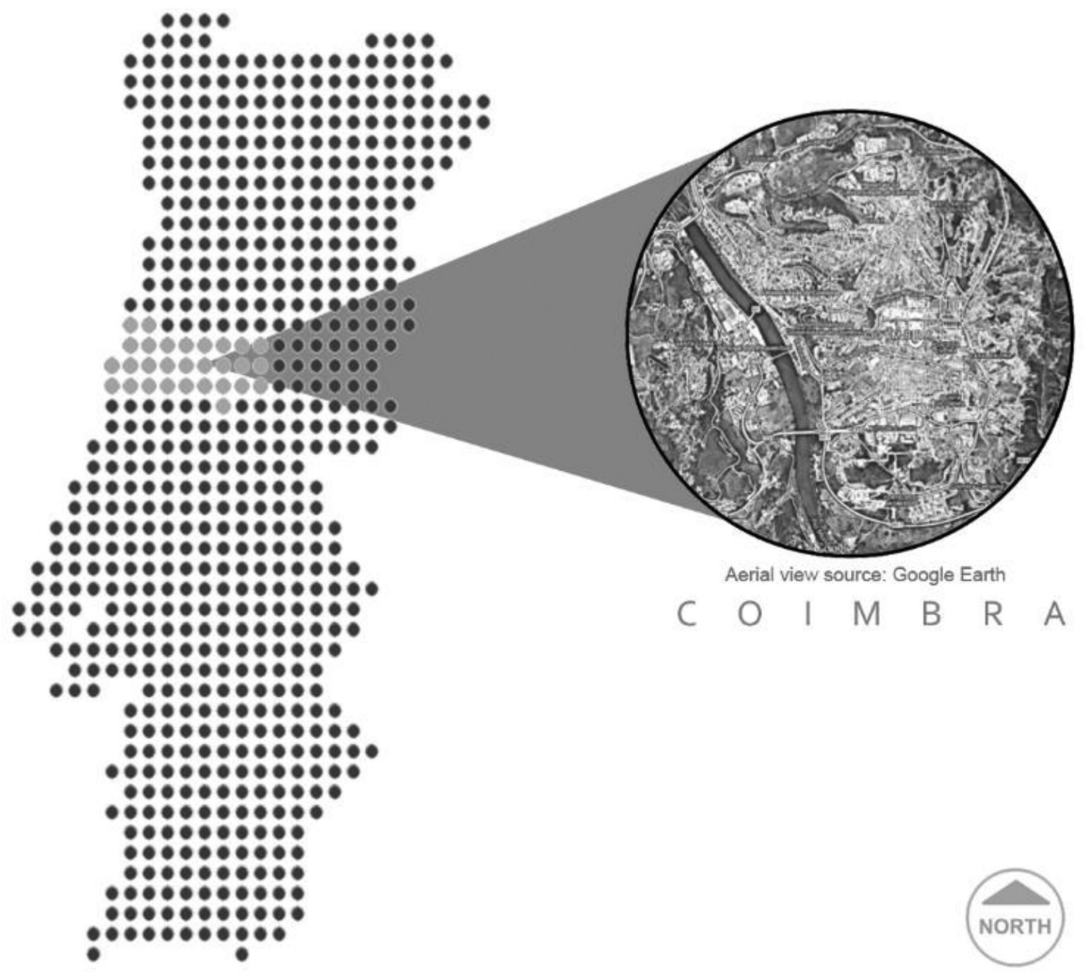

Figure 1: Coimbra, Portugal.

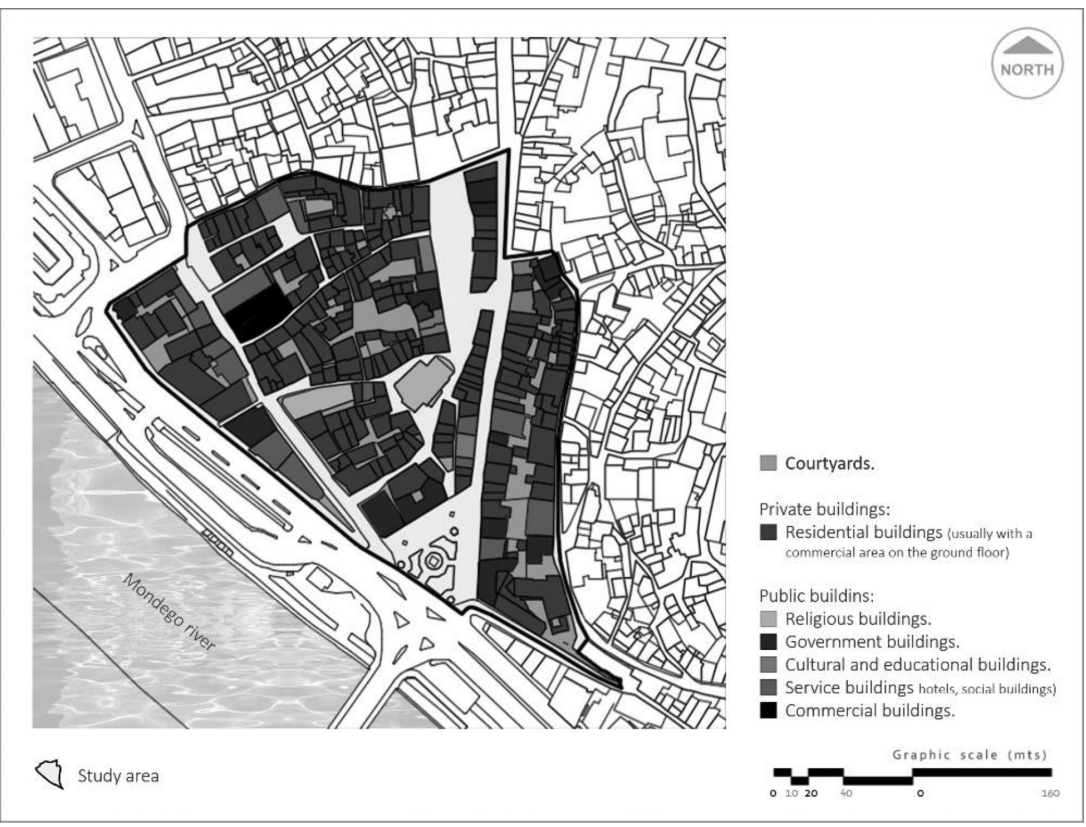

Figure 2: Study case - Baixa of Coimbra, Portugal. 
"D" or a satisfactory practice, this mean that the Baixa neighborhood is over the conventional practice, but it is not as good as it is expected related to have a sustainable management.

Management is a long-term issue. The neighborhood management system need to find a dialogue between the population density and population need, with the administrative institutions, because it is only in this way that the plans and strategies of management, control and maintenance of the area will be properly chosen, and the actions to perform will lead to better benefits for the neighborhood and its users, so the four analyzed criteria of Baixa neighborhood have to find a balance in order to improve its management level, as until now it is doing well just in two of the four criterions.

\section{CONCLUSIONS}

Finally, it is important to understand that in the built city, the urban development is increasingly concerned with detecting hidden potential (social, economic, cultural, spatial) to enable innovation and to balance conflicting goals between the concepts of sustainable development and urban planning, the aspect which until the last decade the conception of this two concepts was done separately. However, in the last years the panorama of urban planning has been changing, by going beyond its typical perception of design, technical and legal aspects; introducing the necessity of being delimited by organizational measures, communication and cooperation with public and private agents, as well as the need to adopt an action plan that improves the decision-making during all the stages of the project. This mode of action goes by the name of "Management".

But the management term does not replace planning, but expands it to include communication, monitoring, maintenance and organizational elements. This expansion generates different stages of management, like the planning management, information and participatory management, strategic resources management, project and quality management, use and operational management, adaptation or redevelopment management, between others.

Currently, the study and evaluation of the different stages of management promotes a quality-oriented urban sustainable development, which serves primarily to ensure permanent innovation in the built city and its civil society structures and entities, and presents a new mode of looking forward to a cooperative management. Is for this reason that the Management indicators emerged as one of the existing sustainable indicators available in the market, but until now, the determination to deepen on its study has been vainly.

Nevertheless, the current path of our chaotic cities like the increasingly decentralized complicated planning and decision-making processes, make it necessary to require locally specific actions, and optimally transparency; is with this motivation that the UISA methodology went into the study and understanding of the "Management indicator" in existing neighborhoods, in order to give a measuring instrument to promote the increase of urban sustainability. Becoming the analysis of this indicator of extreme importance as is the reflection of the organization and the correct function of a place.

\section{ACKNOWLEDGMENTS}

Jocelyn Erandi Reyes Nieto gratefully acknowledges the support from the Consejo Nacional de Ciencia y Tecnología (CONACyT) and the FCT (Portuguese Foundation for Science and Technology). 


\section{REFERENCES}

[1] Kyrkou, D. \& Karthausa, R., Urban sustainability standards: predetermined checklists or adaptable frameworks? Procedia Engineering, 21, pp. 204-211, 2011. http://dx.doi.org/10.1016/j.proeng.2011.11.2005

[2] Reyes Nieto, J.E., Simões da Silva, L., Murtinho, V, Rigueiro, C. \& Gonçalves, A., Ejemplificación de la problemática actual de las ciudades latinoamericanas, a través del análisis de Santiago de Querétaro, Euro-ELECS 2015 Latin-American and Europena Conference on Sustainable Buildings and Communities, Connecting People and Ideas, Guimarães. Portugal, pp. 1837-1846, 2015.

[3] Reyes Nieto, J.E., Simões da Silva, L., Murtinho, V. \& Rigueiro, C., An overview of existing methodologies for evaluating sustainability at the urban level. In $X$ Congresso de Construção Metálica e Mista, eds. L. Simões da Silva, P. Vila Real, J. Rocha de Almeida, R. Gonçaves, cmm Press, Coimbra, Portugal. pp. 81-90, 2015.

[4] Moussiopoulos, N., Achillas, C., Vlachokostas, C. \& Spyridi, D., Environmental, social and economic information management for the evaluation of sustainability in urban areas: a system of indicators for Thessaloniki, Greece. Cities, 27, pp. 377-384, 2010.

http://dx.doi.org/10.1016/j.cities.2010.06.001

[5] UNESCO. Educating for a Sustainable Future: A Transdisciplinary Vision for Concerted Action, 1997. EPD-97/CONF.401/CLD.1

[6] Salat, S., Cities and Forms: on Sustainable Urbanism, Editions Hermann: France, 2011.

[7] BREEAM Communities, Technical Manual: SD202, BRE Global Limited, 2012.

[8] International Organizational for Standardization. ISO 9000: International Standards for Quality Management, International Organization for Standardization: Genéve, Switzerland, 1992.

[9] Lopes, C., City center revitalization in Portugal. Lessons from two medium size cities. Cities, 17, pp. 19-31, 2000. http://dx.doi.org/10.1016/S0264-2751(99)00049-9

[10] Nieto, J., da Silva, L., Murtinho, V., Rigueiro, C. \& Gonçalves, A., Conceptual model for the sustainable rehabilitation of medium-size inner cities in Europe: Coimbra, Portugal. Journal of Urban Planning and Development, 2016. http://dx.doi.org/10.1061/(ASCE)UP.1943-5444.0000303 